\title{
Secondary rock ore reserve recovery using a primary rock layout: Extensión Hw Pipa Norte, a case study
}

\author{
F Hidalgo CODELCO, Chile \\ I Salinas CODELCO, Chile
}

\begin{abstract}
For Panel Caving mine projects, extraction level design plays a crucial role in determining productivity and the amount of investment required. In existing literature regarding gravitational flow of broken ore, the general rule of thumb is that the finer the fragment size of the rock, the closer the drawpoints need to be. This is in order to maximize ore recovery through interactive draw between the drawpoints. In the present study, we analyze a particular case that serves as an exception to this general rule. The case involved is a subsector of El Teniente Mine in Chile, called Extensión Hw Pipa Norte (EHPN), where the layout is spaced $20 \mathrm{~m}$ between drawpoint drifts and $30 \mathrm{~m}$ between production drifts. The predominant rock type is secondary rock, which has a mean fragment size below $25 \mathrm{~cm}$. With this layout and rock combination, a low reserve recovery (below 90\%) is expected since the draw ellipsoids are expected to interact at great height, thus leaving a considerable amount of remnant ore left unmined above the crown pillars. In order to measure ore reserve recovery, we calculate the quotient between extracted ore and planned reserves, the latter selected and estimated through various technical and economic criteria during the pre-production planning phase. Reserve recovery is calculated for the sector as a whole, as well as for each individual drawpoint. Results indicate a total of $97 \%$ reserve recovery for EHPN as a whole, while $70 \%$ of the drawpoints managed to exceed $90 \%$ in individual recovery. These numbers prove quite interesting, as a more spaced layout reduces the amount of drift development requirements for the same amount of footprint area, which means a lighter investment for the same level of income. Furthermore, a more spaced layout generates more resistant crown pillars, which in turn allows for the construction of larger drifts and thus allows for the use of larger haulage equipment. This has a direct positive impact on productivity. It is worth noting that the base of the exploited block is composed of primary ore, while the rest of the block is predominantly composed of secondary ore. Due to this, combined with what was discussed above, delving deeper into the physical phenomenon behind this case should prove useful to validate and extend its applications to future mining projects with similar characteristics.
\end{abstract}

\section{Introduction}

For any mining project to be deemed successful, it needs to maximize ore reserve recovery, where ore reserves are all geological resources determined to be technically and economically viable for extraction. According to gravitational flow theory, ore extraction from drawpoints generates ellipsoids of broken ore flow, which move according to density differentials. Assuming the drawpoints are not exceedingly distant from each other, and that there is a certain level of discipline and uniformity in the draw, the draw ellipsoids should connect and interact with one another, favoring a better ore flow towards the drawpoints. This minimizes the amount of unrecovered ore above the crown pillars, as shown in Figure 1. 


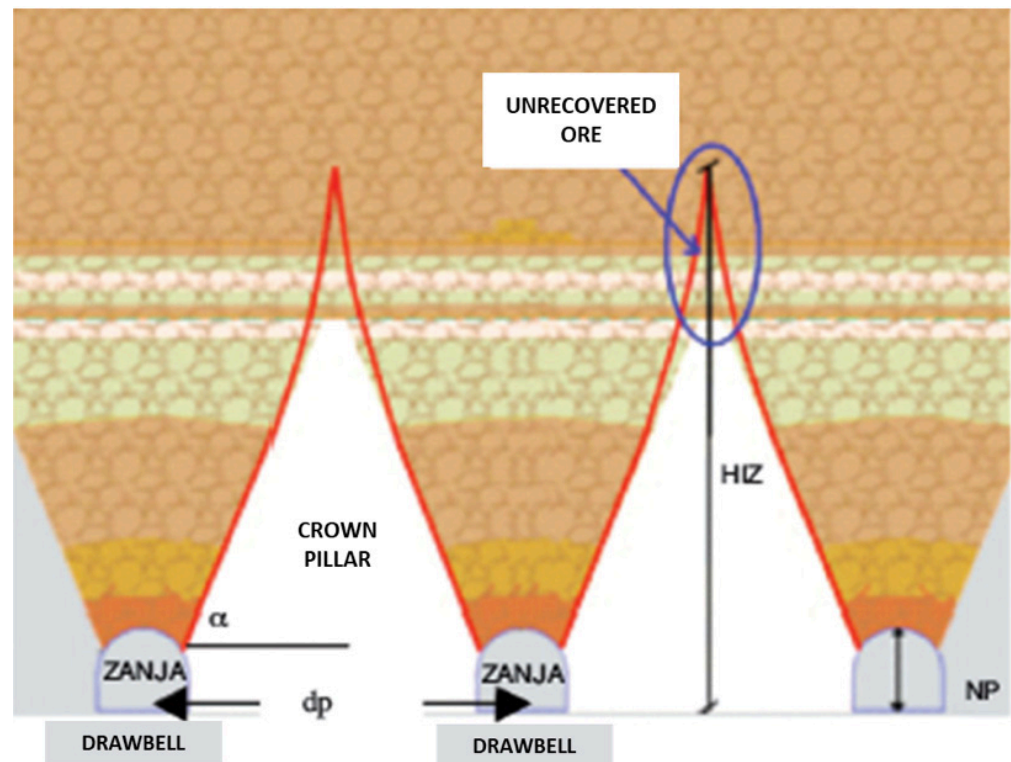

Figure 1 Interaction between draw ellipsoids (Castro et al. 2012)

From the above figure we can deduce a simple equation which links the height of the interaction zone $(\mathrm{HIZ})$, the ore's repose angle $(\alpha)$, the distance between drawpoint drifts (Dp) and the width of those same drifts (Wp):

$$
H I Z=\frac{\left(D_{p}-w_{p}\right)}{2} \tan (\alpha)
$$

This equation shows that ore reserve recovery is inversely proportional to HIZ. Considering that $\alpha$ is an intrinsic property of the broken ore, and that Wp generally does not vary in large proportions, it is safe to say that - in theory - reserve recovery depends strongly on drawpoint spacing, which is completely a design variable.

For materials of smaller grain size, the repose angle is greater, due to greater cohesion between particles. Thus, according to equation (1), the finer the ore will break, the more compact the layout design needs to be (less drawpoint spacing) in order to maximize reserve recovery. Before delving into the case study, we will look briefly at existing literature on this subject.

According to Laubscher, there is a close relationship between the diameter of the draw ellipsoids, also known as drawzones, and the grain size of the broken ore. Using experimental and empirical data, he constructs the following figure, in which the diameter of the isolated drawzone (IDZ) diameter is expressed as a function of ore fragmentation. This well-known figure has often been used for layout design.

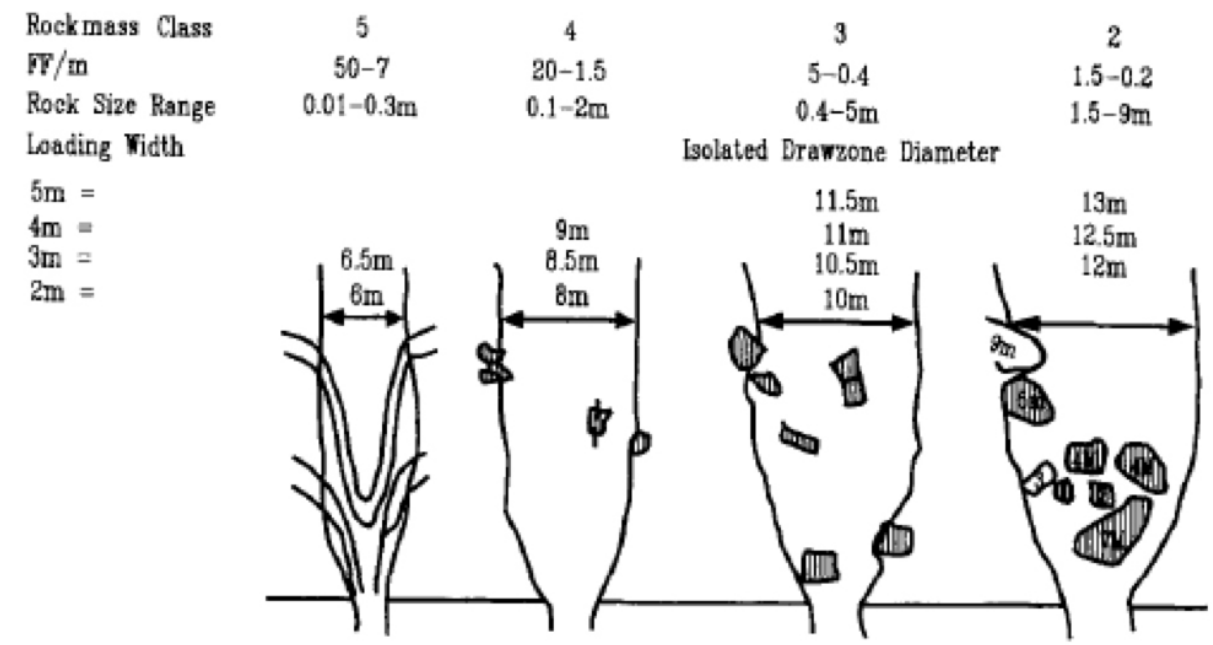

Figure 2 Isolated drawzone diameter v/s Rock size (Laubscher 1994) 
Laubscher used sand-model tests to determine that interaction between drawzones occurs at 1.5 times the isolated drawzone diameter, and that the interaction improves as drawpoints are closer together within the layout. This can be observed in the following examples:

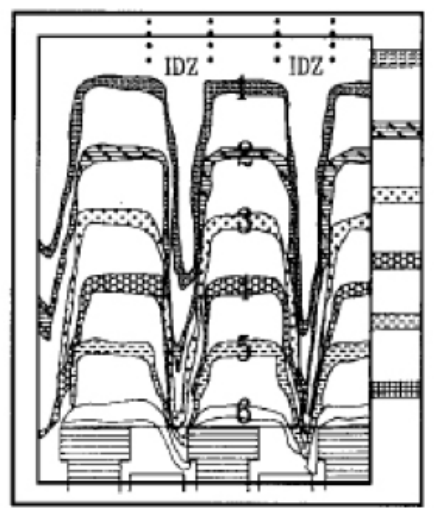

A. D/Ps @ $2.2 \times$ IDZ DIAM. DIL. ENTRY $15 \%$

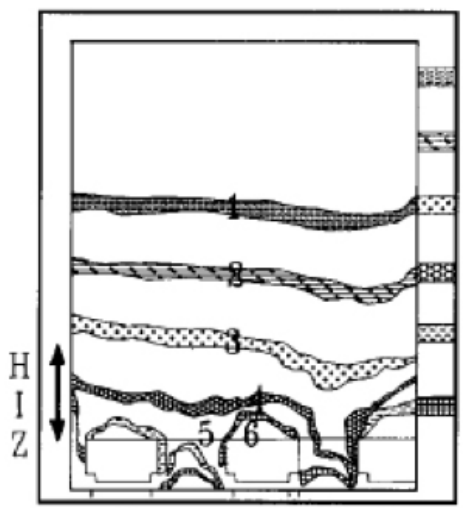

C. D/Ps $91.1 \times$ IDZ DIAM. DIL. ENTRY $85 \%$

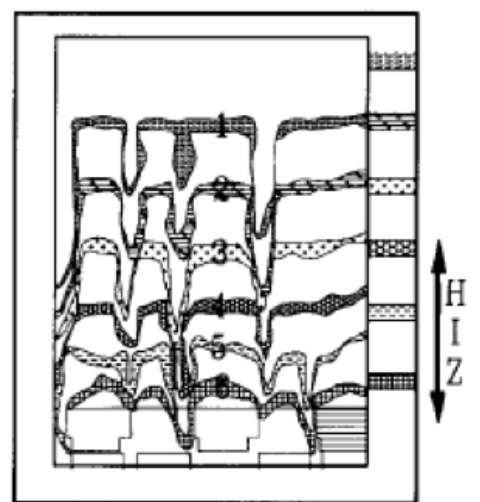

B. D $/ \mathrm{Ps} 1.5 \mathrm{x} \mathrm{IDZ} \mathrm{DIAM}$ DIL. ENTRY $60 \%$

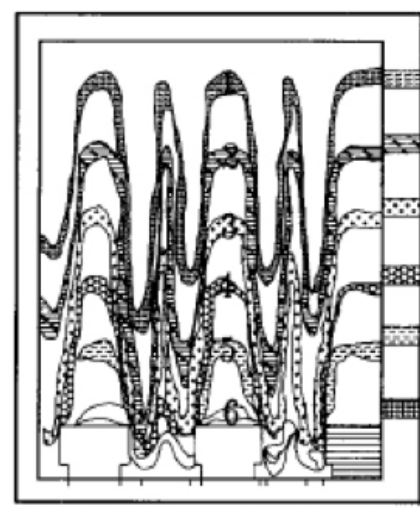

D. DPs a $1.1 \times$ IDZ WORKED IN ISOLATION DIL. ENTRY 25\%

Figure 3 Drawzone interaction with varying drawpoint spacing (Laubscher 1994)

Therefore, we can conclude that a narrowly spaced layout is clearly beneficial from a reserve recovery standpoint. However, there are a few drawbacks to deal with. A compact layout means constructing more drawpoint drifts, which is more expensive. Also, the crown pillar between drifts becomes smaller and thus stability could be compromised. Therefore, all three variables come into consideration when defining the mine design.

In the present case study, El Teniente mining complex, through a small mining sector called Extensión Hw Pipa Norte, recovered a large portion of the ore reserves, even though these reserves were composed mostly of secondary ore (fine fragmentation), and the layout design considered a wide space between drawpoints. This study illustrates this exploitation experience as a counterexample to the paradigm discussed in this chapter, as well as the potential benefits of its application to future caving projects.

\section{Extensión Hw Pipa Norte}

\subsection{Overview and design}

Extensión Hw Pipa Norte (EHPN) is a panel cave mine with a 10,800 $\mathrm{m}^{2}$ footprint located at 2190 m.a.s.l. (extraction level), with an average column height of $220 \mathrm{~m}$. This mining sector is a continuation to the west of an operating sector called Pipa Norte (PN). Neighboring EHPN to the north is a depleted mine called Quebrada Teniente (QT). 
In order to minimize the costs and time involved in constructing the project, EHPN uses the same material

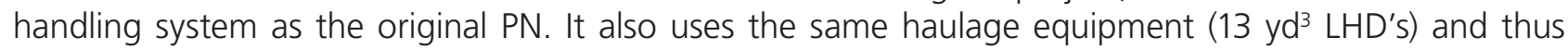
implements the same extraction level layout, which consists of a Teniente-type layout with $30 \mathrm{~m}$ between production drifts and $20 \mathrm{~m}$ between drawpoint drifts.
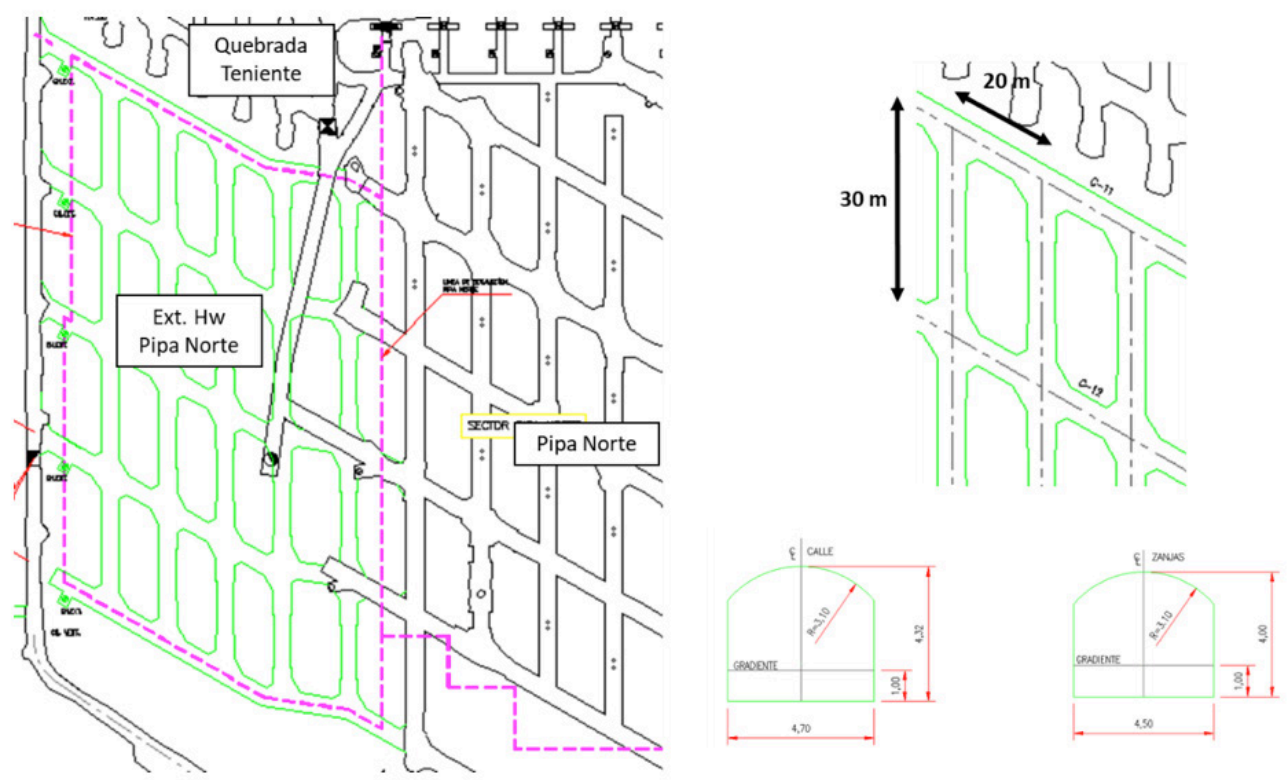

Figure 4 Extensión Hw Pipa Norte extraction level-layout and design parameters

As for geology, the most relevant aspect of the sector is the dominant presence of secondary ore (over $80 \%$ of the block), which has a small fragment size (below $25 \mathrm{~cm}$ average) because of its alteration due to its proximity to the surface. Figure 5 shows an evolution of geotechnical composition as we go up the column.
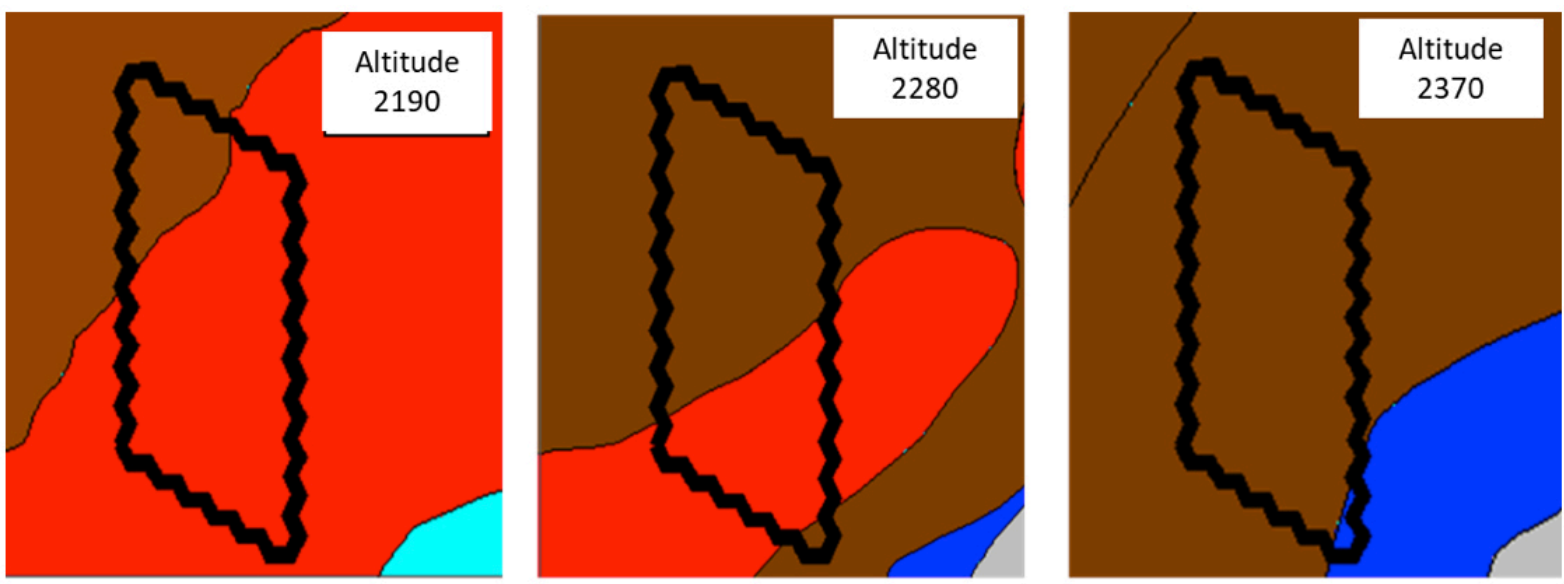

\begin{tabular}{|c|c|c|c|c|c|}
\hline COLOR & \multicolumn{2}{|c|}{ GETOTECHNICAL UNIT } & RELATIVE CAVEABILITY & RELATIVE FRAGMENTATION & GEOTECHNICAL QUALITY \\
\hline & \multirow{5}{*}{ Primary Ore } & Zone 1 & Very Poor & Very Coarse & Very High \\
\hline & & Zone 2 & Poor & Coarse & High \\
\hline & & Zone 3 & Average & Average to Coarse & Average to High \\
\hline & & Zone 4 & Average to High & Average & Average \\
\hline & & Zone 5 & High & Fine & Poor \\
\hline & \multicolumn{2}{|c|}{ Secondary Ore } & Very High & Very fine & Very poor \\
\hline
\end{tabular}

Figure 5 Geotechnical characterization EHPN: altitudes 2190 (extraction level), 2280 and 2370 [masl]

The predominant relative fragmentation ranges from "fine" to "very fine", meaning that the average rock size will be in the $0.1-1 \mathrm{~m}$ range. According to Laubscher's criterion, drawpoint spacing should be at most $13.5 \mathrm{~m}$ in order to secure interactive draw. The actual drawpoint spacing in the final design is 20 $\mathrm{m}$ (determined by the adjacent Pipa Norte), so one could expect isolated draw and thus a considerable portion of unrecovered ore. 


\subsection{Pre-production planning}

EHPN is not located below any previously depleted sectors (in-situ rock all the way to the surface), but it is adjoined to both QT and PN. Therefore, the main factors that will define planned ore reserves are ore grade, surface topography, and lateral reserve contamination. The resulting exercise is the planned extractable column height, differentiated per drawpoint, as shown in Figure 6.

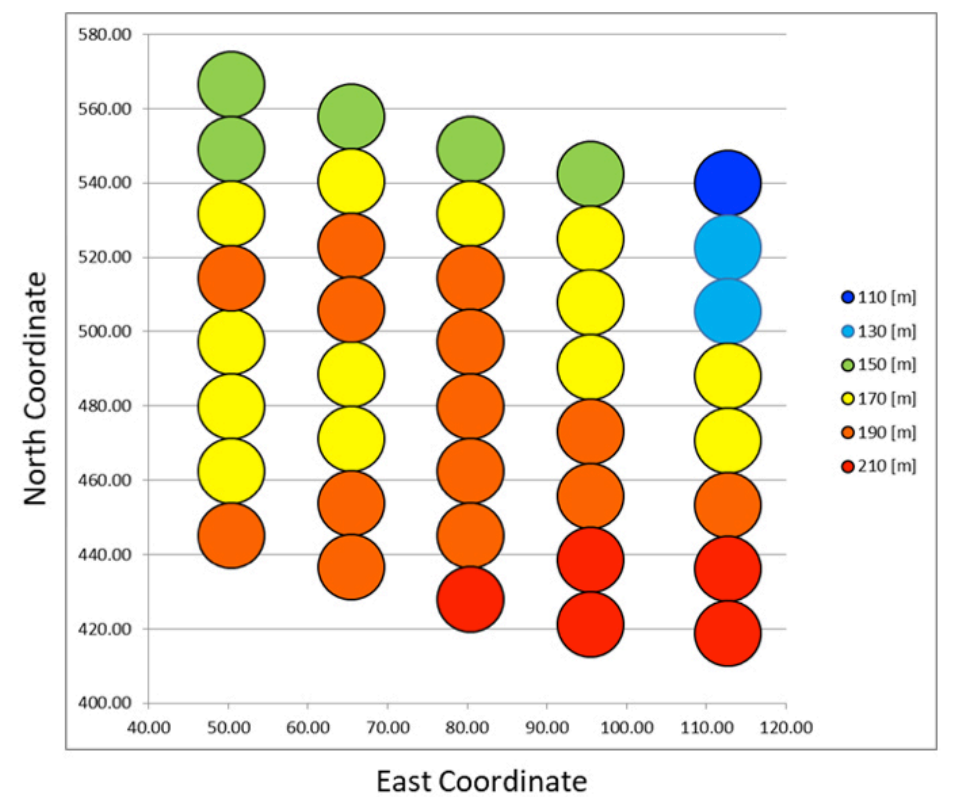

Figure 6 Planned extraction per drawpoint, expressed in column height [m]

Considering the planned extraction per drawpoint and the amount of available drifts, EHPN's mining plan is prepared for a life of mine period of 4.8 years, obtaining the production vector shown in Figure 7. According to this vector, expected ore reserves total 4.92 Mton with a mean ore grade of $0.82 \%$ CuT, equivalent to 40.1 kton of contained fine copper (ktf). Nonetheless, according to the explanation in the Introduction above, a low reserve recovery is expected due to the combination of fine ore extracted through a widely spaced layout.

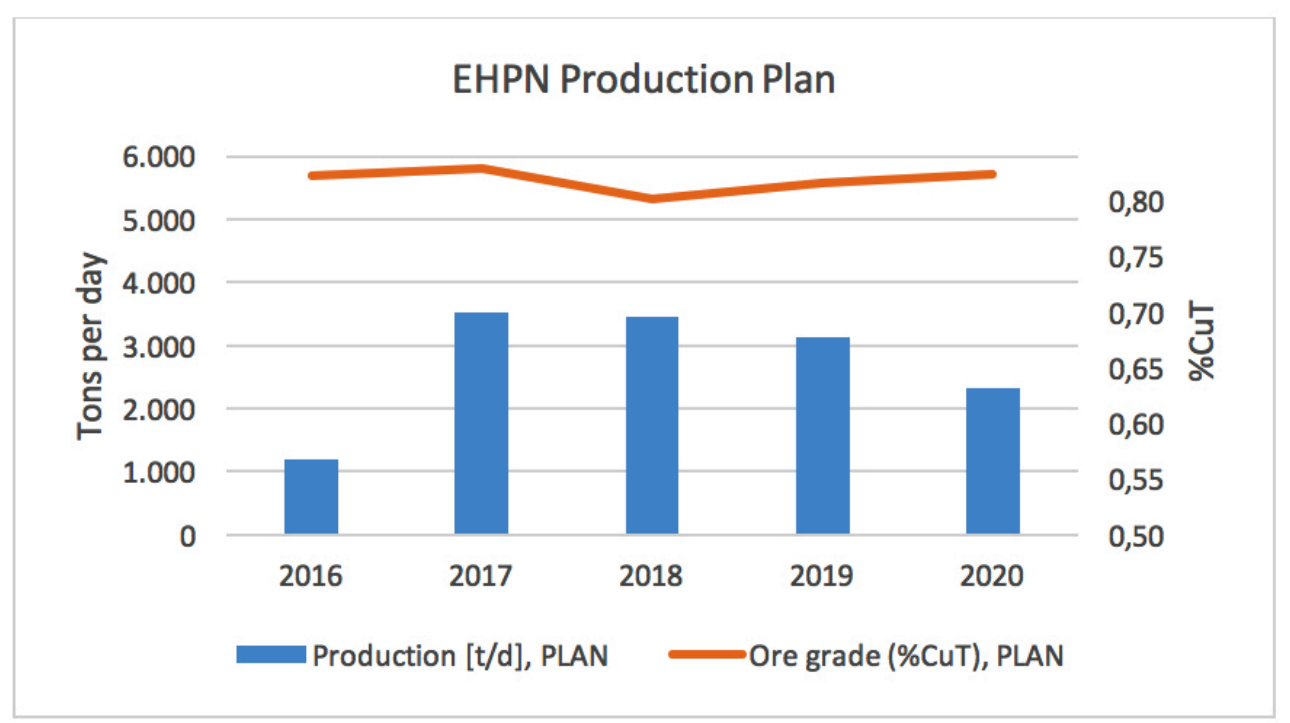

Figure 7 Production plan, EHPN 


\subsection{Quality control and assurance}

Quality control and assurance for the extraction and drilling/blasting processes plays a key role in determining the success of a mining project. In particular, in El Teniente there are two governing bodies associated with this type of QA/QC, whose functions (among many others) are the following:

- Production Management Superintendence (PMS), in charge of constructing short-term plans for mine production and area commissioning, in accordance with the mid-term planning strategy and technical recommendations issued by the Rock Mechanics department. Day-to-day control of plan compliance, as well as blast-by-blast control of the mucked material.

- Mining Engineering Superintendence (MES), in charge of the drilling and blasting design, as well as ground control for the correct implementation of the design on site.

In terms of drilling and blasting, four variables are controlled:

- Length of the drillhole v/s design - MES

- Portion of the drillhole that is loaded with explosives - MES

- Blasting sequence - MES

- Extraction of blasted material from previous blast - PMS

The following figure illustrates an example of an undercut blast, comparing design drill length and explosive load with the actual performance. The sequence has been proposed by operations and validated by MES. Combined with appropriate ground control from PMS, MES and operations, drill and blast QA/ QC guarantees optimal performance of the caving method with minimal risk.

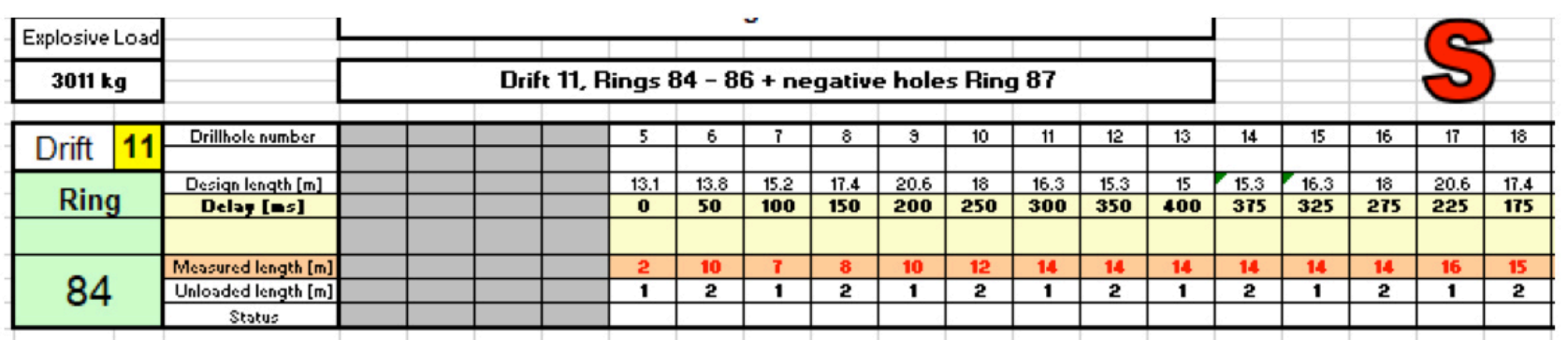

\begin{tabular}{|c|c|c|c|c|c|c|c|c|c|c|c|c|c|c|c|c|c|c|c|}
\hline \begin{tabular}{l|l} 
Drift & 11
\end{tabular} & Drillhole number & 1 & 2 & 3 & 4 & 5 & 6 & 7 & 8 & 9 & 10 & 11 & 12 & 13 & 14 & 15 & 16 & 17 & 18 \\
\hline \multirow{2}{*}{ Ring } & Design length [m] & 9.6 & 7.9 & 73.9 & 13.3 & 73.1 & 73.8 & 75.2 & $\pi 7.4$ & 20.6 & 18 & 16.3 & 75.3 & 15 & 75.3 & 16.3 & 18 & 20.6 & $7 \pi .4$ \\
\hline & Delay [as] & 500 & 550 & 600 & 650 & 700 & 750 & 800 & 850 & 900 & 950 & 1000 & 1050 & 1100 & 1075 & 1025 & 975 & 925 & 875 \\
\hline & & & & & & & & & & & & & & & & & & & \\
\hline \multirow{3}{*}{85} & Mesaured length [m] & 8 & 8 & 12 & 8 & 9 & 9 & 14 & 15 & 17 & 16 & 16 & 15 & 16 & 14 & 18 & 16 & 19 & 17 \\
\hline & \begin{tabular}{|l|l|} 
Unlooded length [m] \\
\end{tabular} & 4 & 4 & 4 & 2 & 1 & 2 & 1 & 2 & 1 & 2 & 1 & 2 & 1 & 2 & 1 & 2 & 1 & 2 \\
\hline & Stotus & & & & & & & & & & & & & & & & & & \\
\hline
\end{tabular}

\begin{tabular}{|c|c|c|c|c|c|c|c|c|c|c|c|c|c|c|c|c|c|c|c|}
\hline Drift & Drillhols number & 1 & 2 & 3 & 4 & 5 & 6 & 7 & 8 & 9 & 10 & 11 & 12 & 13 & 14 & 15 & 16 & 17 & 18 \\
\hline Dritt & & & & & & & & & & & & & & & & & & & \\
\hline \multirow{2}{*}{ Ring } & Design length [m] & 9.6 & 7.9 & 13.9 & 13.3 & 13.1 & 13.8 & 15.2 & 17.4 & 20.6 & 18 & 16.3 & 15.3 & 15 & 15.3 & 16.3 & 18 & 20.6 & 77.4 \\
\hline & Delay [ns] & 1200 & 1250 & 1300 & 1350 & 1400 & 1450 & 1500 & 1550 & 1600 & 1650 & 1700 & 1750 & 1775 & 1725 & 1675 & 1625 & 1575 & 1525 \\
\hline \multirow{3}{*}{86} & Mesaured length [m] & 8 & 5 & 8 & 14 & 9 & 12 & 15 & 17 & 17 & 17 & 17 & 9 & 15 & 15 & 16 & 17 & 18 & 17 \\
\hline & Unloaded length [m] & 4 & 4 & 4 & 4 & 1 & 2 & 1 & 2 & 1 & 18 & 1 & 2 & 1 & 2 & 1 & 2 & 1 & 2 \\
\hline & Stotus & & & & & & & & & & & & & & & & & & \\
\hline
\end{tabular}

\section{Figure 8 Blast quality control sheet, example}

With regards to the extraction process, PMS creates a monthly production plan for each sector, drawpoint per drawpoint. This takes into account the area commissioning requirements, seismic control, dilution control, maintenance activities, productivity, and ore grade. Short-term programming also considers up to date information, such as the results of systematic ore sampling, which allows for opportune adjustments. Compliance with this plan is controlled on a daily, weekly and monthly basis. 


\section{$3 \quad$ Results}

Figure 9 illustrates the total real production of EHPN compared to the original mine plan. We can observe an anticipated consumption of ore reserves, which is reflected in higher production during 2017 and 2018 , as well as in the early closure of the mine sector. The latter is also related to the initiation as well as the optimization of other mine sectors with higher ore grade.

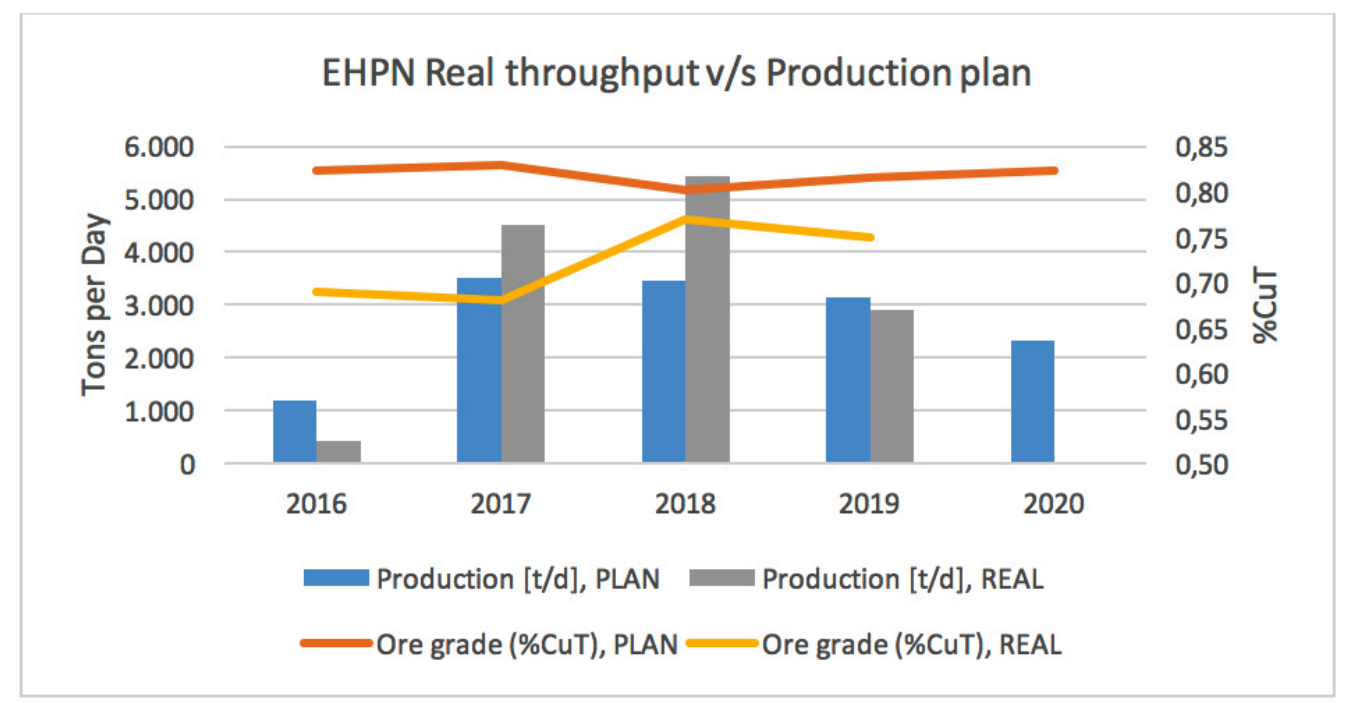

\section{Figure 9 Real extraction v/s mine plan, EHPN}

In total, $4.78 \mathrm{Mton}$ of ore were extracted at a mean ore grade of $0.73 \%$ CuT, equivalent to $34.9 \mathrm{ktf}$. This amounts to a global reserve recovery of $97 \%$ in tonnage and $87 \%$ in copper content. Because ore grade is not of interest to this study, we will be referring to recovery only in terms of tonnage. The following figures illustrate individual drawpoint reserve recovery.

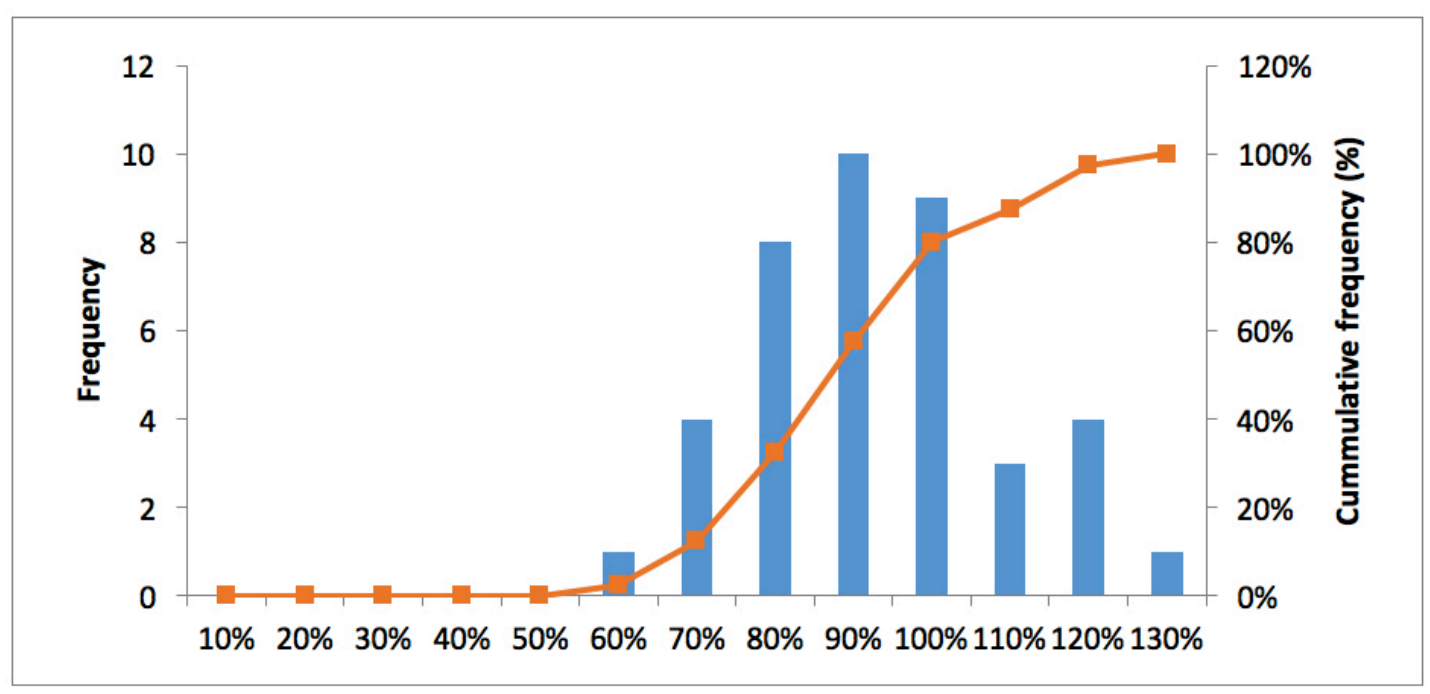

Figure 10 Reserve recovery (\% tonnage), histogram 


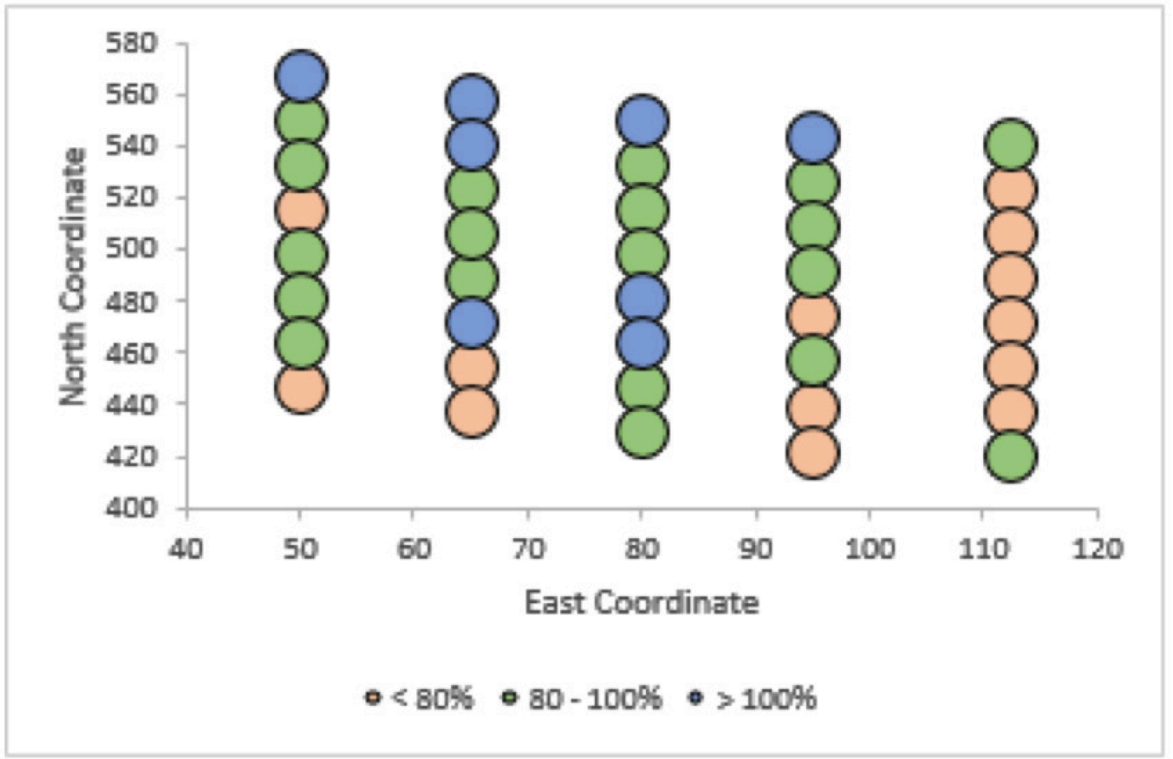

Figure 11 Reserve recovery (\% tonnage), geographic distribution

The following observations can be made regarding this data:

- Overall high reserve recovery, with over-compliance in some drawpoints and under-compliance concentrated in the eastern border (restrictions on extraction due to observed dilution from Pipa Norte) and the southern border (difficulty of caving propagation without any neighboring assisting cavities).

- High adherence to the mining plan in general, reflected in the fact that $70 \%$ of the drawpoints exceed $90 \%$ recovery, and $90 \%$ exceed $80 \%$ recovery. This could be indicative of uniform draw.

For visual complementation of extraction data, Figures 12 and 13 illustrate the change in the crater that EHPN generates on the surface, between the beginning and end of the life of mine. We can appreciate a harmonic descent of the crater over time, as well as the absence of pronounced sinkholes. The latter would be indicative of isolated draw in one or more drawpoints.

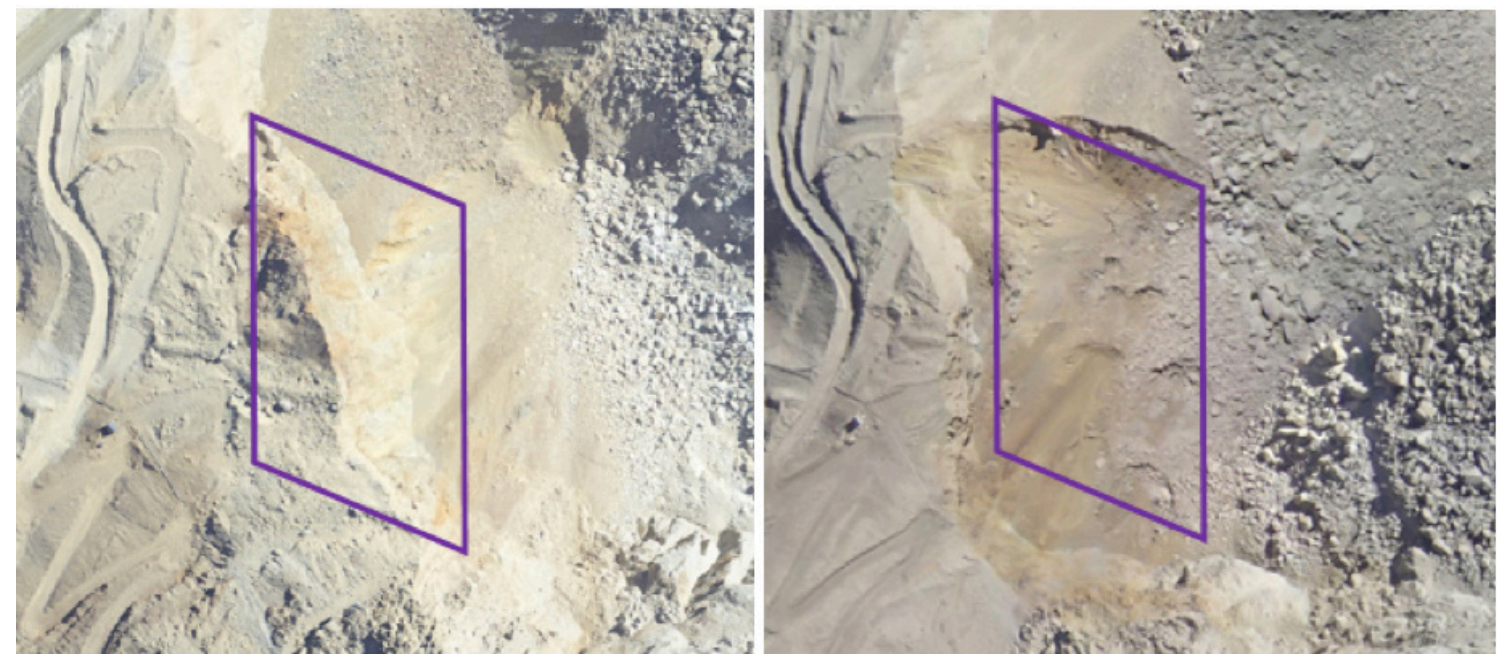

Figure 12 Aerial photography of the surface. 2016 (left), 2019 (right). EHPN footprint outlined in purple 


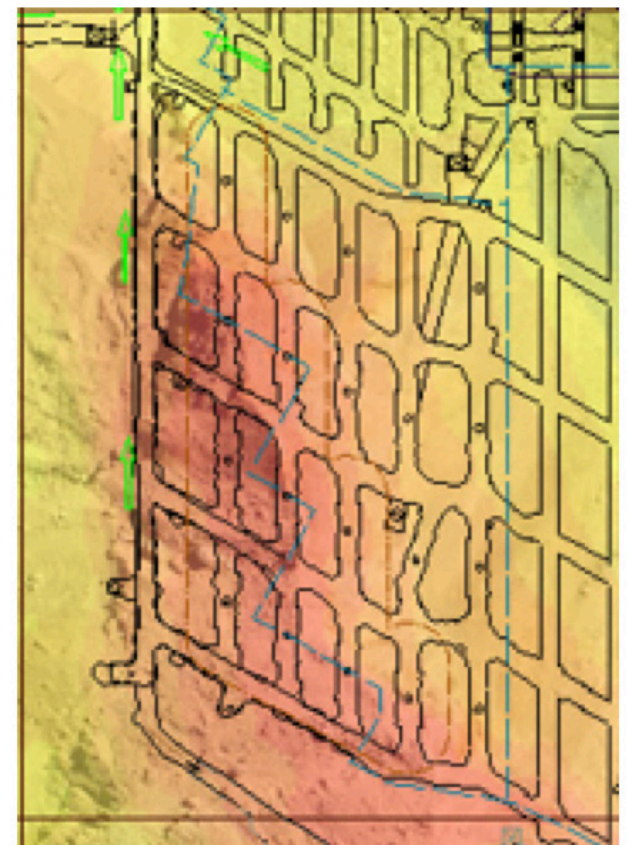

\section{Altitude difference between} 2016 and 2019 [m]

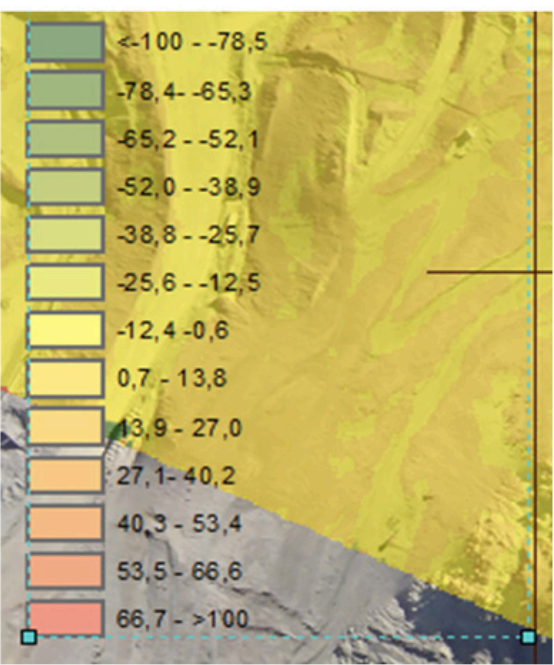

Figure 13 Surface altitude differential, 2016 - 2019, heat map

Additionally, images of drawpoints are shown below in order to display grain size and other visual characteristics of the extracted ore, which contains a high presence of secondary ore.
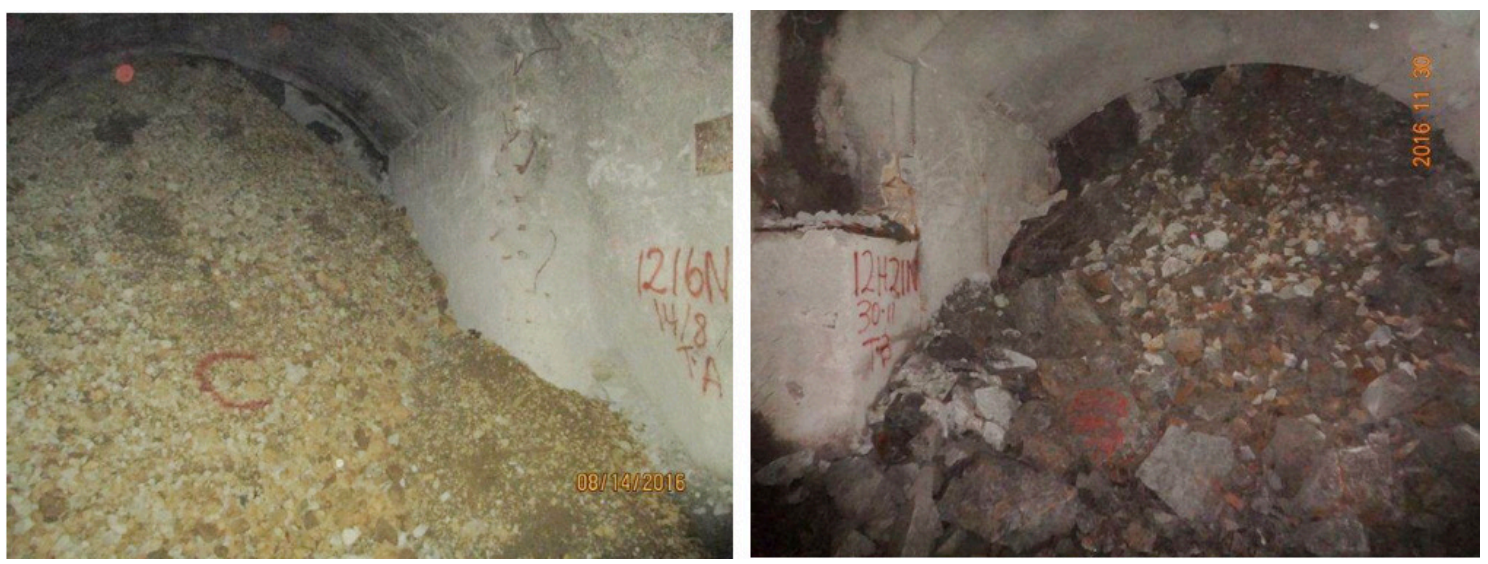

\section{Figure 14 EHPN drawpoints}

Regarding the relationship between mine design - heavily influenced by the adjacent Pipa Norte - and reserve recovery, and considering that reserve recovery was not higher only due to low ore grades (which were about $0.6 \% \mathrm{Cu}$ at EHPN's closing stage, still above the short term cut-off grade of $0.4 \% \mathrm{Cu}$ ), we would like to calculate the positive effect that a wider layout has on the construction costs (CAPEX). If we had followed the classical approach recommended by Laubscher, the drawpoint spacing would have been $13.5 \mathrm{~m}$ instead of $20 \mathrm{~m}$. In turn, we would have had to build more drawpoint drifts and more drawpoint frames, and more intersections would have had to be fortified with cables. Considering all other mining works to be constant, the comparison for the different layout designs is detailed in Table 1. 
Table 1 CAPEX comparison for two layouts with different drawpoint spacing (source for unit price: Mine development department, El Teniente)

\begin{tabular}{|c|c|c|c|c|c|c|}
\hline Item & Unit & $\begin{array}{c}\text { Unit Price } \\
\text { [US\$/un] }\end{array}$ & $\begin{array}{c}\text { Quantity } \\
\text { [un] } \\
\mathbf{3 0 \times 2 0} \\
\text { Layout }\end{array}$ & $\begin{array}{c}\text { Cost [US\$] } \\
\mathbf{3 0 \times 2 0} \\
\text { Layout }\end{array}$ & $\begin{array}{c}\text { Quantity [un] } \\
\mathbf{3 0 \times 1 3 . 5} \text { Layout }\end{array}$ & $\begin{array}{c}\text { Cost [US\$] } \\
\mathbf{3 0 \times 1 3 . 5} \text { Layout }\end{array}$ \\
\hline $\begin{array}{c}\text { Drawpoint } \\
\text { Frame }\end{array}$ & un & $\$ 22,615$ & 40 & $\$ 904,600$ & 64 & $\$ 1,447,360$ \\
\hline $\begin{array}{c}\text { Intersection } \\
\text { Fortification }\end{array}$ & un & $\$ 3,064$ & 25 & $\$ 76,600$ & 40 & $\$ 122,560$ \\
\hline Drawpoint Drift & m & $\$ 3,288$ & 600 & $\$ 1,972,800$ & 960 & $\$ 3,156,480$ \\
\hline TOTAL & & & & $\$ 2,954,000$ & & $\$ 4,726,400$ \\
\hline
\end{tabular}

The difference in CAPEX between both cases is 1.77 MUS\$. Considering EHPN's total built area is 10,800 $\mathrm{m}^{2}$, the difference in mine preparation unit costs is $164 \mathrm{US} \$ / \mathrm{m}^{2}$. El Teniente's average mine preparation unit cost is approximately $2,800 \mathrm{US} \$ / \mathrm{m}^{2}$, which means that the wider layout is $6 \%$ cheaper.

\section{Conclusions and recommendations}

Analysis of the extraction data and crater descent images allows for the conclusion that EHPN is indeed a counterexample to a general theoretical layout design rule in which drawpoint spacing must be smaller, the finer the fragment size of the ore.

Because it is an extension of an existing sector, EHPN's mine design was oriented to maximize synergy with existing infrastructure (in particular the adjacent Pipa Norte) in order to minimize investment (CAPEX). This was a higher priority at the design stage of the project than the relationship between drawpoint spacing and reserve recovery.

Therefore, if the experience of this case study is applied to future projects of similar characteristics, a spaced layout for fine ore extraction could considerably reduce CAPEX, especially for larger footprints. Furthermore, a wider layout leaves more robust crown pillars, which in turn allows for the construction of larger drifts and thus allows for the use of larger haulage equipment. This has a positive impact on productivity (tons per hour), which is directly proportional to the size increase in loading capacity (bucket size for an LHD, for example).

A key factor in the successful experience of EHPN lies in the rigor behind the extraction process. From design and planning all the way to the operation itself, including a robust production control organization, all involved entities come together to maximize profits and productivity while minimizing operational hazards. In particular, quality control and assurance in the drilling and blasting process is vital in securing interaction between drawpoints. This includes strict control of drilling, explosive loading and mucking. Furthermore, systematic visual inspections and ore sampling throughout the life of mine are crucial in assuring that each extracted ton is profitable, as well as allowing for opportune adjustments and optimizations in short-term scheduling.

Finally, we recommend delving deeper into the physical phenomenon behind this case study, where the quality of the information could be enriched by drillhole data and sampling in the crown pillars so as to empirically estimate HIZ. With further evidence to support the case, it could be possible to complement the existing literature without contradicting gravitational flow theory, allowing Panel Caving mines with certain characteristics to use more flexible mine design rules. In particular, this case study focuses on a rock mass where the base of the block is composed of primary ore (coarse fragmentation), and the rest is composed mostly of secondary ore (fine fragmentation). This could favor drawzone interaction during the initial caving stage, which in turn could favor secondary ore flow during the later steady caving stage. 


\section{References}

Castro, R, De la Huerta, F \& Vargas, R 2012, 'Determination of drawpoint spacing in panel caving: a case study at the El Teniente Mine', The Journal of The Southern African Institute of Mining and Metallurgy, vol. 112, pp. 871-876.

Cavieres, P, Contreras, E \& Arce, JC 2005, 'Dimensionamiento de mallas de extracción, bateas recolectoras y pilar corona para método Panel Caving en roca primaria', Annual mining engineering symposium, Universidad de Santiago, in Spanish.

Laubscher, DH 1994, 'Cave mining - the state of the art', The Journal of The Southern African Institute of Mining and Metallurgy, vol. 94, pp. 279-293. 